\title{
Simulation of grassland productivity by the combination of ground and satellite data
}

\author{
F. Maselli ${ }^{\mathrm{a}, *}$, G. Argenti $^{\mathrm{b}}$, M. Chiesi $^{\mathrm{a}}{ }^{\text {, L. Angeli }}{ }^{\mathrm{c}}$, D. Papale $^{\mathrm{d}}$ \\ a IBIMET-CNR, Via Madonna del Piano 10, 50019 Sesto Fiorentino (FI), Italy \\ b DISPAA-University of Firenze, P.le delle Cascine 18, 50144 Firenze, Italy

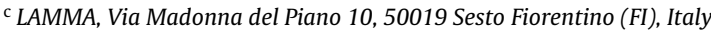 \\ d DIBAF-University of Tuscia, Via S. Camillo Lellis, 01100 Viterbo, Italy
}

\section{A R T I C L E I N F O}

\section{Article history:}

Received 20 December 2011

Received in revised form 31 October 2012

Accepted 19 November 2012

Available online 19 January 2013

\section{Keywords:}

Grassland

C-Fix

BIOME-BGC

GPP

NPP

NDVI

MODIS

\begin{abstract}
A B S T R A C T
This paper presents the assessment of a NDVI-based parametric model (C-Fix) and a bio-geochemical model (BIOME-BGC) for the simulation of semi-natural grassland primary productivity in Italy. The two models are first calibrated using the gross primary productivity (GPP) data of an eddy covariance flux tower placed over a Mediterranean-temperate hilly area in Central Italy. Next, they are applied to estimate the net primary productivity (NPP) of three independent areas representative of different eco-climatic zones. The first area shows a typical Alpine climate, while the other two are characterized by more or less pronounced Mediterranean features. The accuracy of the NPP estimates is assessed through comparison with destructive dry matter measurements taken in the three areas. The results obtained support the capability of the two models to predict spatial NPP differences across the various grassland sites. The greatest estimation errors are found in the mountain area, mostly due to inaccuracies in the meteorological input data. These errors affect particularly the outputs of the bio-geochemical model and are mitigated by the use of C-Fix, which exploits the remotely sensed information related to the seasonal evolution of green biomass.
\end{abstract}

(c) 2012 Elsevier B.V. All rights reserved.

\section{Introduction}

Grasslands represent one of the ecosystems most widespread in the world and cover a significant proportion (about 40\%) of emerged land excluding Greenland and Antarctica (FAO, 2005). They are characterized by a variety of growth forms and functions, not only related to their productivity but also to their importance in maintaining biodiversity and open landscapes (Coppa et al., 2011). Primary grasslands generally occupy areas where tree growth is hampered by eco-climatic conditions, such as unfavorable thermal and rainfall regimes and/or low soil fertility. Secondary grasslands are widespread in areas where trees have been removed and in abandoned fields. Grasslands, in fact, generally show water and nutrient requirements lower than forests and can rapidly colonize new environments (Soussana et al., 2007).

Most natural and semi-natural grasslands are used for feeding livestock. Estimating the gross and net productivity of these grasslands is therefore important for both scientific and practical reasons. For example, the estimation of grassland productivity

\footnotetext{
* Corresponding author. Tel.: +39 055 5226024; fax: +39 055444083

E-mail address: maselli@ibimet.cnr.it (F. Maselli).
}

can allow proper resource management, such as the evaluation of the carrying capacity to reduce pasture degradation (Argenti et al., 2011). Different kinds of models have been developed and applied to this aim, with variable levels of complexity and accuracy (Soussana et al., 2004; Matsushita et al., 2004; Turner et al., 2006). Some of these models are based on complex ecological algorithms which link carbon, water and nutrient cycles, while others utilize remotely sensed data, such as satellite images (Goetz et al., 1999; Paruelo et al., 2004; Boschetti et al., 2007).

The most utilized remote sensing based methods which estimate gross and net primary productivity (GPP and NPP) of grasses are based on Monteith's approach (Monteith, 1966, 1972). This approach defines the dry matter productivity for a given time period as the total intercepted Absorbed Photosynthetically Active Radiation (APAR) multiplied by the Radiation Use efficiency (RUE). APAR is generally obtained by multiplying incoming PAR by an estimate of the fraction of PAR absorbed by vegetation (fAPAR), which is derivable from various types of remotely sensed vegetation indices (Baret and Guyot, 1991; Bannari et al., 1995).

Monteith's models are generally efficient but cannot simulate all ecosystem functions which are important for NPP assessment (such as autotrophic respirations and allocations). This limit can be overcome by the application of more sophisticated bio-geochemical 
models, which can simulate all functions and processes of terrestrial ecosystems (Running and Hunt, 1993). These models, however, require an efficient calibration phase and accurate input data layers to work properly (Cramer et al., 1999; Chiesi et al., 2011). This operationally limits their applicability over large areas and/or for long time periods.

The current study aims at evaluating the possible application of two different models to simulate the primary productivity of Italian semi-natural grasslands. In particular, a Monteith's type parametric model, C-Fix, is tested for grassland GPP assessment (Veroustraete et al., 2004; Maselli et al., 2009a), while the bio-geochemical model BIOME-BGC is evaluated to simulate also respiration and allocation functions (Running and Hunt, 1993; White et al., 2000).

The investigation utilizes the GPP data taken by an eddy covariance flux tower in Central Italy over a 2 -year period to calibrate both models. The predictive performances of the two models are then assessed through comparison with destructive NPP measurements collected in three independent areas representative of different eco-climatic conditions. The main properties of the two models are finally analyzed in view of their possible operational application.

\section{Models applied}

\subsection{C-Fix}

C-Fix is a Monteith's type parametric model which was originally developed to simulate the carbon fluxes of forest ecosystems. The model is driven by temperature, radiation and the fraction of absorbed photosynthetically active radiation (fAPAR), quantified through its linear relationship with the normalized difference vegetation index (NDVI) (Veroustraete et al., 2002, 2004). NDVI, which is mathematically defined as NDVI $=[\mathrm{NIR}-R] /[\mathrm{NIR}+R]$ where NIR stands for near infrared reflectance $(0.7-1.1 \mu \mathrm{m}$ wavelength) and $R$ stands for red reflectance (0.6-0.7 $\mu \mathrm{m}$ wavelength), is related to plant photosynthetic activity and particularly to fAPAR (Baret and Guyot, 1991; Bannari et al., 1995).

C-Fix combines NDVI-derived fAPAR with incoming solar radiation and air temperature derived from ground measurements in order to simulate total photosynthesis (Veroustraete et al., 2004). The model is conceptually simple and can use inputs averaged over different time periods. The daily GPP $\left(\mathrm{g} \mathrm{C} \mathrm{m}^{-2} \mathrm{day}^{-1}\right)$ of an ecosystem can be computed as

$\mathrm{GPP}=\varepsilon_{\text {max }} \cdot T_{\text {cor }} \cdot \mathrm{fAPAR} \cdot \mathrm{PAR}$

where $\varepsilon_{\max }$ is the maximum radiation use efficiency $(\varepsilon), T_{\text {cor }}$ is a factor accounting for the dependence of photosynthesis on air temperature and fAPAR is the fraction of PAR absorbed by the vegetation, all referred to the day examined.

Maselli et al. (2009a) have recently proposed a modification of C-Fix aimed at improving the model performance in Mediterranean areas, which are characterized by a long summer dry season during which vegetation growth is limited by water availability (Bolle et al., 2006). This new version includes an additional correction factor, Cws, that limits photosynthesis in case of short-term water stress (Maselli et al., 2009a). The factor is derived from a simplified water balance which uses as input rainfall and potential evapotranspiration. More precisely, Cws is computed as:

Cws $=0.5+0.5 \frac{\mathrm{AET}}{\mathrm{PET}}$

where AET and PET are actual and potential evapotranspiration, respectively, both cumulated over a two month period. AET is assumed to equal precipitation when this is lower than PET. Consequently, Cws can vary between 0.5 (when short-term water shortage reduces photosynthesis to half of its potential value) and
1 (when there is no water shortage and photosynthesis reduction) This modification is completed by the use of the MODIS temperature correction factors (Heinsch et al., 2003) in place of the original factors proposed by Veroustraete et al. (2002).

\subsection{BIOME-BGC}

BIOME-BGC is a bio-geochemical model developed at the University of Montana to estimate the storage and fluxes of water, carbon and nitrogen within terrestrial ecosystems (Running and Hunt, 1993). It requires daily climate data, information on the general environment (i.e. soil, vegetation and site conditions) and parameters describing the ecophysiological characteristics of vegetation. BIOME-BGC is capable of finding a quasi-climax equilibrium with local eco-climatic conditions through the spin-up phase, whose aim is to quantify the initial amount of all carbon and nitrogen pools; after that, it proceeds with a normal simulation which estimates all respiration and allocation processes corresponding to the requested study years (White et al., 2000; Churkina et al., 2003). The modelling of quasi-climax condition implies that the sum of all simulated respirations becomes nearly equivalent to GPP, which makes annual NPP approach heterotrophic respiration and net ecosystem exchange (NEE) tend to zero. The version of the model currently used (4.2) includes complete parameter settings for several biome types, among which C3 and C4 grasslands (White et al., 2000).

\section{Study areas and data}

\subsection{GPP calibration site}

The eddy covariance flux measurements for model calibration were derived from the Amplero study site. This site is located in Central Italy on a gently undulated area, at $884 \mathrm{~m}$ a.s.l. (Table 1, Fig. 1). The climate is Alpine-Mediterranean. Long-term mean annual precipitation is $1365 \mathrm{~mm}$ and mean annual temperature is about $10^{\circ} \mathrm{C}$ (ARSSA local database). Soil, defined as a Haplic Phaeozems, is poorly drained. Soil depth is more than $1 \mathrm{~m}$, and the percentage of clay is $56 \%$.

Vegetation composition of the Amplero grassland was characterized by Balzarolo (2008) during a field campaign carried out in 2004. The site is covered by few dominant graminoids (belonging to genus Poa), legumes (mainly Trifolium and Medicago) and forbs (Geranium and Cerastium). The area was cultivated up to about 50 years ago, after which it has been managed by a combination of cutting/harvesting and cattle grazing. Usually, grass is harvested in June and cattle grazing is then allowed till the end of the year. Considering the mean number of animals in the site, Balzarolo (2008) estimated that grazing has a negligible effect on local carbon balance.

The Amplero site belongs to the FLUXNET project (http://fluxnet. ornl.gov/site/528), a network coordinating regional and global analysis of observations from micrometeorological tower sites. The site is equipped with an eddy covariance tower for continuous measurements of $\mathrm{CO}_{2}$ and $\mathrm{H}_{2} \mathrm{O}$. The tower has collected data from spring 2002 to summer 2008. These data were processed according to state of the art methodology (Papale et al., 2006). Quality analysis was performed according to the stationarity and integral turbulence tests (Foken and Wichura, 1996). Gap filling and flux partitioning were applied to derive GPP and ecosystem respiration, according to Reichstein et al. (2005). The reliability of the GPP observations was ensured by the selection of years containing less than one month of missing or low quality flux data. This criterion led to identify 2 years (2003 and 2004); only data from those years were therefore used in the current work. 
Table 1

Geographical position of the four grassland areas and main features of relevant ground measurements.

\begin{tabular}{|c|c|c|c|c|c|c|}
\hline Area & Coordinates & $\begin{array}{l}\text { Elevation ( } \mathrm{m} \text { asl. } \\
\text { from 1-km DEM) }\end{array}$ & Ground measurements & Sampling dates & $\begin{array}{l}\text { Number of destructive } \\
\text { samples }\end{array}$ & $\begin{array}{l}\text { Number of } \\
\text { sample groups }\end{array}$ \\
\hline Amplero & $\begin{array}{l}41^{\circ} 54^{\prime} 17.8 \mathrm{~N} \\
13^{\circ} 36^{\prime} 22.3 \mathrm{E}\end{array}$ & 834 & Daily eddy covariance fluxes & 2003-2004 & & \\
\hline Comelico & $\begin{array}{l}46^{\circ} 39^{\prime} 50 \mathrm{~N} \\
12^{\circ} 27^{\prime} 17 \mathrm{E}\end{array}$ & $1880-2200$ & Destructive DM samples & $\begin{array}{l}29 / 08 / 2006 \\
28 / 08 / 2007 \\
26 / 08 / 2008\end{array}$ & 8 & 3 \\
\hline Mugello & $\begin{array}{l}44^{\circ} 04^{\prime} 18 \mathrm{~N} \\
11^{\circ} 23^{\prime} 25 \mathrm{E}\end{array}$ & $666-684$ & Destructive DM samples & $\begin{array}{l}21 / 09 / 2006 \\
20 / 09 / 2007\end{array}$ & $\underline{5}$ & $\underline{2}$ \\
\hline Maremma & $43^{\circ} 04^{\prime} 34 \mathrm{~N}$ & 341 & Destructive DM sample & $\begin{array}{l}29 / 06 / 2004 \\
3 / 06 / 2005 \\
7 / 06 / 2006 \\
18 / 05 / 2007\end{array}$ & 2 & 1 \\
\hline
\end{tabular}

\subsection{NPP validation areas}

The destructive samplings of accumulated biomass used for model validation were taken during measurement campaigns planned and conducted with the main aim of characterizing the pasture vegetation types. These measurements were collected in three areas, whose main characteristics are briefly described below (Table 1, Fig. 1):

1. Comelico, in the Eastern Alps (Veneto Region). Different pasture types are placed at an altitude ranging from 1850 to $2050 \mathrm{~m}$ a.s.l. Soils are represented by shale-clay (siliceous) and calcareous-dolomite. The mean annual temperature is $2.7^{\circ} \mathrm{C}$ and the mean annual precipitation is $1288 \mathrm{~mm}$ (Targetti et al., 2010). Main species are represented by Festuca gr. rubra L. and Nardus stricta L.
2. Mugello, in a hilly area of North Apennines (Tuscany Region). Semi-natural grasslands are placed at an elevation of 660-680 m a.s.l. Soil is silt-loam, the mean annual temperature is $11.3^{\circ} \mathrm{C}$ and the mean annual rainfall is $1178 \mathrm{~mm}$ (Messeri, 2009). Main herbaceous species are represented by Brachypodium rupestre (Host) Roem. \& Schult. and Bromus erectus Huds.

3. Maremma, in a gently rugged area of South Tuscany. Seminatural herbaceous resources are placed at an elevation of $410 \mathrm{~m}$ a.s.l. Soil is clay-sandy, the mean annual temperature is $13.8^{\circ} \mathrm{C}$ and the mean annual rainfall is $885 \mathrm{~mm}$ (Staglianò et al., 2008). Most representative species are Dactylis glomerata L. and Lolium sp.

In the above described areas, samples of vegetation ( $1 \mathrm{~m}^{2}$ wide) were harvested to ground level and fresh biomass was then taken to the laboratory, oven-dried for $48 \mathrm{~h}$ at $80^{\circ} \mathrm{C}$ and weighted in order

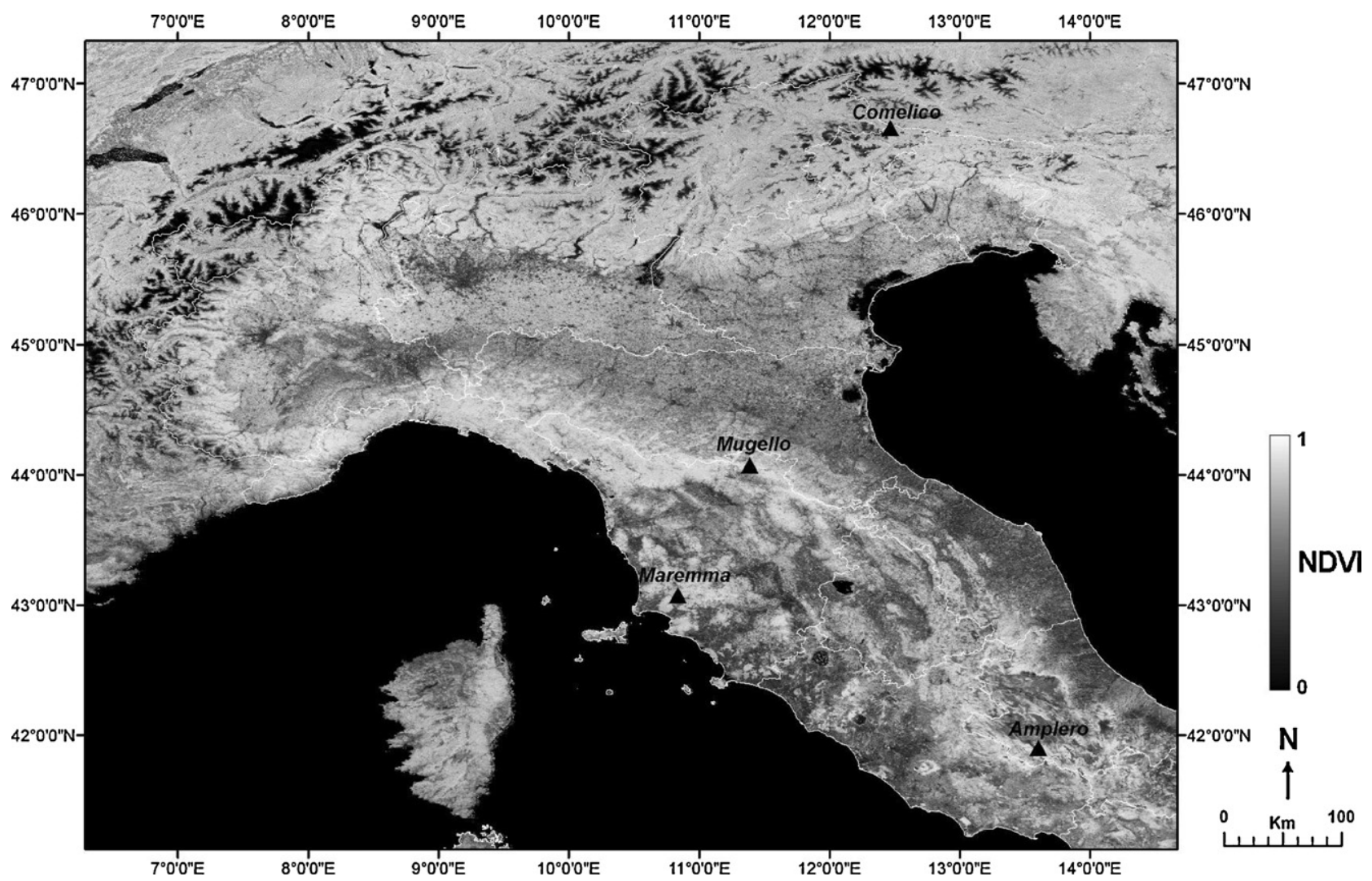

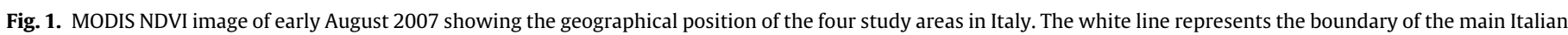
administrative units. 
to determine the dry matter (DM) content and the total biomass productivity accumulated until the date of harvesting. Field measurement campaigns were conducted in different years: from 2006 to 2008 (Comelico), in the biennium 2006-2007 (Mugello) and from 2004 to 2007 (Maremma). The number of destructive samples collected in each study area is reported in Table 1.

\subsection{Meteorological data}

Daily weather measurement series were available only for the Amplero site and were anyway insufficient to drive the two models considered. For this reason, basic daily weather variables (minimum and maximum temperature and precipitation) were derived from the E-OBS dataset (Haylock et al., 2008; van den Besselaar et al., 2011). This is a dataset designed for use in a wide range of applications which has a grid spacing of $0.25^{\circ}$ and a time period coverage from 1950 to present. The dataset has been recently downscaled to $1-\mathrm{km}$ resolution by the use of a digital elevation model (DEM) for a 10-year period (2000-2009) (Maselli et al., 2012). The same study shows that the accuracy of the downscaled dataset is high for daily temperatures (particularly maximum), and lower for rainfall.

\subsection{NDVI data}

MODIS NDVI images were downloaded from the NASA website (ftp://e4ftl01.cr.usgs.gov/MOLT/). The MODIS NDVI 16-days composite product (MOD13Q1) is computed starting from band reflectances corrected for atmospheric and BRDF effects and masked for water, clouds, heavy aerosols, and cloud shadows. Data are provided every 16 days at $250-\mathrm{m}$ spatial resolution. Version5 MODIS/Terra Vegetation Indices products are Validated Stage 2, meaning that accuracy has been assessed over a widely distributed set of locations and time periods via several ground-truth and validation efforts (http://lpdaac.usgs.gov). The NDVI product is distributed in tiles covering different portions of the Earth surface. All images of the tiles corresponding to Northern, Central and Southern Italy were downloaded for the years 2000-2009. These images were corrected for residual atmospheric disturbances as described in Maselli et al. (2009a).

\section{Data processing}

\subsection{Calibration of C-Fix and BIOME-BGC}

The two considered models were first of all calibrated using the flux tower measurements of Amplero. C-Fix was in fact originally developed for forest ecosystems and its application to Mediterranean grasslands requires appropriate tuning of the main model drivers, i.e. the maximum light use efficiency and the temperature and water stress factors. As regards BIOME-BGC, the parameter settings proposed by White et al. (2000) for C3 grasslands must be modified to adapt to Mediterranean eco-climatic conditions. More specifically, a calibration is required concerning the BIOME-BGC eco-physiological parameters related to $\mathrm{CO}_{2}$ uptake, which control all main transpiration and productivity processes (Chiesi et al., 2007).

As previously mentioned, the daily meteorological data needed to drive the two models were derived from the available ground measurements and the downscaled E-OBS dataset. More particularly, in the case of Amplero daily minimum and maximum temperatures were extracted from the corresponding 1-km pixel of the E-OBS dataset. Concerning rainfall, the measurements taken by the tower were primarily considered, complemented with the 1-km downscaled E-OBS data to fill the measurement gaps. Daily minimum and maximum temperatures and rainfall were then used to predict air humidity and solar radiation through the MT-CLIM algorithm (Thornton et al., 2000).

The extraction of NDVI values of grasslands needed for fAPAR computation from the $250 \mathrm{~m}$ MODIS imagery was complicated by the possible effects of image geolocation errors (Wolfe et al., 2002). The Amplero grassland is relatively large (both sides of about $800 \mathrm{~m}$ ), but it is surrounded by dense forests, which generally show higher NDVI values (Maselli, 2011). The impossibility of accurately identifying the grassland boundary in each MODIS image led to exclude the application of pixel unmixing methods to retrieve grassland NDVI values (Maselli et al., 1998). These methods, in fact, are sensitive to the size of the observed cover types in relation to the spatial resolution of the satellite imagery used and to its correct superimposition on the reference maps. Some experimental trials confirmed that the application of such methods was problematic in this area, and even more in the three, more fragmented, validation areas (see below). Alternatively, the simplified assumption was used that the pixels most covered by grassland corresponded to those with the lowest NDVI values around the tower site. The validity of this assumption was first checked by examining different NDVI statistics extracted from a $3 \times 3$ pixel window centred on the site (i.e. minimum, median, average). As expected, the minimum NDVI values within this window were the most differentiated from those of the surrounding forest in all seasons. The NDVI values of all 16-day periods examined were therefore extracted in this way and were transformed into the daily values required by C-Fix through linear interpolation. fAPAR was then derived from NDVI through the generalised linear equation proposed by Myneni and Williams (1994).

The calibration of C-Fix consisted in running the model with different values of $\varepsilon$ and of the two correction factors ( $T_{\text {cor }}$ and Cws) in order to optimize the fitting between measured and simulated daily GPP. This operation was carried out in two steps. First, the correlation between the two data series was maximized using various versions of the two factors. More particularly, the MODIS temperature correction function for grasses was modified by varying the daily minimum temperature at which $\varepsilon=\varepsilon_{\max }$ (Heinsch et al., 2003), while Cws was changed by cumulating AET and PET over different periods. Next, $\varepsilon$ was adjusted by minimizing the total model bias.

BIOME-BGC was calibrated following a methodology similar to that described in Chiesi et al. (2007). More precisely, the model was applied in a spin-up-and-go mode (Running and Hunt, 1993), looking for an error minimum of the simulated GPP across varying parameter settings. Attention was focused on two model settings which control total photosynthetic production and response to water stress, i.e. the fraction of leaf nitrogen in rubisco and the maximum stomata conductance (White et al., 2000).

The performances of both models were assessed by comparing the measured and estimated daily GPP values. The agreement between observed and simulated GPP was summarized using the correlation coefficient $(r)$, the root mean square error (RMSE) and the mean bias error (MBE).

\subsection{Simulation of NPP in the three validation areas}

After the calibration, the two models were applied to simulate the NPP of the three independent study areas (Comelico, Mugello and Maremma). As previously mentioned, in these cases destructive measurements of accumulated above ground dry matter were available, taken at various times during different growing seasons (Table 1). The relative adjacency of some sample sites of Comelico and Mugello (distance of 100-200 m) created problems of spatial consistency with the model outputs, whose spatial resolution was mostly determined by the pixel size of the meteorological dataset used $\left(1 \mathrm{~km}^{2}\right)$. In order to make these ground samples consistent with the model estimates and more representative of larger areas, 
Table 2

Main climatic features of the four grassland areas during the study years. The mean length of the growing period is defined as the number of months during which mean temperature exceeds $5{ }^{\circ} \mathrm{C}$ (Pearson and Ison, 1997). The mean length of the dry period is defined as the number of summer months during which mean temperature (in ${ }^{\circ} \mathrm{C}$ ) exceeds twice monthly rainfall (in $\mathrm{mm}$ ) (see Chiesi et al., 2011, for details).

\begin{tabular}{llll}
\hline Area & $\begin{array}{l}\text { Mean annual } \\
\text { rainfall }(\mathrm{mm})\end{array}$ & $\begin{array}{l}\text { Mean length of growing } \\
\text { season (months) }\end{array}$ & $\begin{array}{l}\text { Mean length of dry } \\
\text { period (months) }\end{array}$ \\
\hline Amplero & 1038.0 & 9 & 3 \\
Comelico & 1164.2 & 5 & 0 \\
Mugello & 899.4 & 10 & 1 \\
Maremma & 760.6 & 12 & 3 \\
\hline
\end{tabular}

they were preliminarily grouped. Two-three samples were grouped for each area considering both their geographical adjacency and compositional similarity. Following these criteria, samples were grouped into three sites for Comelico, two sites for Mugello and one site for Maremma (Table 1). In all cases the distance among grouped sites was higher than $1 \mathrm{~km}$.

For all study areas the basic daily weather variables were extracted from the 1-km downscaled E-OBS dataset. Air humidity and solar radiation were then predicted through MT-CLIM. The relatively small sizes of the grasslands (1-5 ha) and their adjacency to forests (less than $200 \mathrm{~m}$ ) exacerbated the previously mentioned problems due to MODIS image pixel size and geolocation error. These problems were addressed by applying the same NDVI extraction method used previously.

The extracted meteorological and NDVI data were used to run the two models in all study areas. In the case of C-Fix the simulation of accumulated DM was carried out considering NPP $\left(\mathrm{gC} \mathrm{m}^{-2} \mathrm{day}^{-1}\right)$ as a constant fraction of GPP. This fraction was set equal to 0.53 (Chen et al., 2003; Zhang et al., 2009). The use of BIOME-BGC permitted a more theoretically correct prediction of NPP by means of the formula:

$\mathrm{NPP}=\mathrm{GPP}-\mathrm{Ra}$

where GPP and Ra are the photosynthesis and autotrophic respiration $\left(\mathrm{g} \mathrm{C} \mathrm{m}^{-2} \mathrm{day}^{-1}\right)$ predicted by the model.

In both cases the model NPP estimates were cumulated from the beginning of the year to the dates of grass harvesting. These estimates were then converted into cumulated above ground dry matter $\left(D_{A G}\right)$ using the following equation:

$\mathrm{DM}_{\mathrm{AG}}=\mathrm{NPP} \cdot 0.33 \cdot 2$

where the multiplication by 0.33 accounts for the allocation of total NPP into cumulated above ground carbon and that by 2 for the conversion from carbon to dry matter (White et al., 2000). The accuracy assessment was performed by comparing all measurements of above ground dry matter to the estimates obtained by C-Fix and by BIOME-BGC. The agreement between data measured and simulated by the two models was summarized again using r, RMSE and MBE.

\section{Results}

\subsection{Calibration of the two models}

The Amplero site is located in a temperate area where grassland growth is limited by temperature from December to February and by water from June to September (Table 2). Mean temperature is relatively low in winter, while water deficit occurs mainly in July-August. The GPP measured by the tower shows a typical bimodal pattern (Fig. 2), with a primary maximum in spring, a summer decline due to water shortage and biomass harvesting and a secondary maximum in autumn. The mean annual GPP is relatively high (about $1400 \mathrm{~g} \mathrm{C} \mathrm{m}^{-2}$ year $^{-1}$ ), but a strong interannual variability is observed. The GPP of 2003 (dry growing season) is about
$1100 \mathrm{~g} \mathrm{C} \mathrm{m}^{-2}$ year $^{-1}$, while that of 2004 (wet growing season) is $1700 \mathrm{~g} \mathrm{C} \mathrm{m}^{-2}$ year $^{-1}$.

The tuning of C-Fix only marginally modifies the model settings used for forest ecosystems. The MODIS temperature correction factor for grassland is optimal, while the water stress index is only slightly changed by computing actual and potential evapotranspiration over a period of one month instead of the original two months (Maselli et al., 2009a). Fig. 3 shows the annual profiles of the model meteorological factors and fAPAR. The two factors are active in different periods, i.e. $T_{\text {cor }}$ in winter and Cws in summer. The fAPAR profiles are bimodal, with a primary maximum in spring, a secondary maximum in autumn and two minima corresponding to the mentioned temperature and water limitation periods and biomass harvesting. Clear differences are also visible in the two study years; in 2003 both Cws and NDVI are particularly low in summer, whilst the opposite is true in 2004. As regards the maximum $\varepsilon$, its optimum value corresponds to $1.65 \mathrm{~g} \mathrm{CMJ}^{-1}$ (APAR). Tuned C-Fix is capable of accurately estimating the daily GPP measured by the flux tower (Fig. 2). The mean predicted GPP is obviously almost identical to the tower measurement. More significantly, predicted daily values closely follow measurements in all seasons, correctly identifying the main GPP minima and maxima. The correlation between measured and estimated data is high and highly significant (0.854) and the RMSE is rather low $\left(1.67 \mathrm{~g} \mathrm{C} \mathrm{m}^{-2} \mathrm{day}^{-1}\right)$.

The optimal calibration of BIOME-BGC is obtained using a fraction of leaf nitrogen in rubisco equal to 0.38 and stomata conductance equal to $0.0027 \mathrm{~m} \mathrm{~s}^{-1}$. The calibrated model gives results slightly poorer than those obtained by C-Fix (Fig. 2); the correlation between measured and estimated data is slightly lower (0.828) and the RMSE higher $\left(1.81 \mathrm{~g} \mathrm{C} \mathrm{m}^{-2} \mathrm{day}^{-1}\right)$. The greatest errors are due to the underestimation of the peak GPP in spring 2004 and to the inaccurate reproduction of some GPP spikes.

\subsection{Simulation of NPP in the three validation areas}

The alpine area of Comelico (around $2000 \mathrm{~m}$ a.s.l.) has a brief growing season (from May to October) due to thermal limitation, while it does not show evident water stress (Table 2). The hilly area of Mugello (about $700 \mathrm{~m}$ a.s.l.) is only marginally affected by thermal limitation, but shows clear water stress in summer. The Maremma hilly area (around $350 \mathrm{~m}$ a.s.l.) is the least affected by thermal limitation and the most limited by water shortage.

According to the previous description, the comparison between measured and simulated data could theoretically rely on three grouped samples for 3 years at Comelico, two samples for 2 years at Mugello and one sample for 4 years at Maremma. The quality of the ground biomass data, however, was found to be low for one season in one of the sites of Comelico and Mugello, which reduced the total number of data points to $15(8+3+4)$. The biomass actually accumulated in the three areas depends not only on local environmental features but also on the different dates of biomass harvesting. Low mean DM measurements $\left(275 \mathrm{~g} \mathrm{DM} \mathrm{m}^{-2}\right.$ year $^{-1}$ ) are found at Comelico at the end of the short growing season. The highest DM values $\left(400 \mathrm{~g} \mathrm{DM} \mathrm{m}^{-2}\right.$ year $^{-1}$ ) are obtained in the temperate area of Mugello at the end of September. The lowest DM values found in the Mediterranean area of Maremma (233 $\mathrm{g} \mathrm{DM} \mathrm{m}^{-2}$ year $^{-1}$ ) are mostly due to the early harvesting period (June), which prevents the consideration of the biomass accumulated in summer.

The diversified eco-climatic features of the three grassland areas are reflected in the corresponding mean annual profiles of C-Fix drivers ( $T_{\text {cor, }}$ Cws and fAPAR) (Fig. 4). The two meteorological factors follow a clear gradient from the most humid area of Comelico to the driest area of Maremma. In the alpine area of Comelico the simulated photosynthetic activity is restricted to about five months due to thermal limitation. In the other two areas 


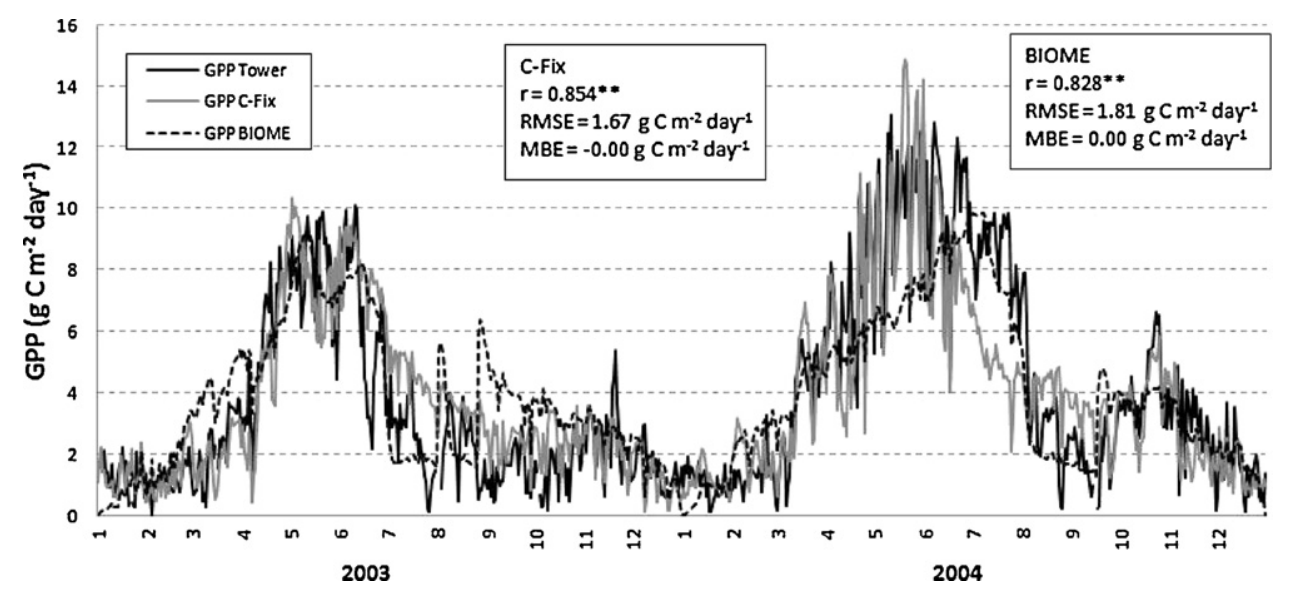

Fig. 2. Daily GPP values measured and simulated by C-Fix and BIOME-BGC for the Amplero site.

Table 3

Mean annual GPP and autotrophic respiration predicted by C-Fix and BIOME-BGC for the three validation areas.

\begin{tabular}{llll}
\hline Area & $\begin{array}{l}\text { C-Fix GPP } \\
\left(\mathrm{g} \mathrm{C} \mathrm{m}^{-2} \mathrm{day}^{-1}\right)\end{array}$ & $\begin{array}{l}\text { BIOME-BGC GPP } \\
\left(\mathrm{g} \mathrm{C} \mathrm{m}^{-2} \mathrm{day}^{-1}\right)\end{array}$ & $\begin{array}{l}\text { BIOME-BGC Ra } \\
\left(\mathrm{g} \mathrm{C} \mathrm{m}^{-2} \mathrm{day}^{-1}\right)\end{array}$ \\
\hline Comelico & 1099 & 844 & 333 \\
Mugello & 1660 & 1647 & 843 \\
Maremma & 1640 & 1482 & 763 \\
\hline
\end{tabular}

plants are growing throughout the entire year, but with a summer minimum due to dryness which is more pronounced in Maremma.

The mean GPP simulated by C-Fix and BIOME-BGC over the whole growing season varies in the three areas depending on relevant drivers (Table 3 ). The first model simulates a maximum annual GPP for the two study areas in Central Italy, Mugello and Maremma (1600-1700 $\mathrm{g} \mathrm{C} \mathrm{m}^{-2}$ year $^{-1}$ ), and a GPP of about $1100 \mathrm{~g} \mathrm{C} \mathrm{m}^{-2}$ year $^{-1}$ for the mountain area of Comelico. BIOMEBGC provides a GPP estimate similar for Mugello, slightly lower for Maremma (about $1500 \mathrm{~g} \mathrm{C} \mathrm{m}^{-2}$ year $^{-1}$ ) and decidedly lower for Comelico (about $850 \mathrm{~g} \mathrm{C} \mathrm{m}^{-2}$ year $^{-1}$ ). The three Comelico sites, however, show different GPP estimates due to the mentioned differences in meteorological drivers; the site at lowest altitude shows a GPP much greater than that of the most elevate site $\left(1350 \mathrm{~g} \mathrm{C} \mathrm{m}^{-2}\right.$ year $^{-1}$ versus $600 \mathrm{~g} \mathrm{C} \mathrm{m}^{-2}$ year $\left.^{-1}\right)$, mainly due to higher estimated temperatures.

The GPP predicted by C-Fix up to the harvesting dates is directly converted into relevant NPP and DM estimates through the use of constant coefficients. In this way the model reproduces fairly well the inter-area variability of the DM measurements, whilst this is less the case for intra-area variations (Fig. 5A). The highest discrepancy is found for Comelico, mainly due to the likely inaccurate estimation of the meteorological drivers for two sites (see Section 6.2), while the DM estimates of the other areas are similar to the measured values. As regards BIOME-BGC, the simulated ratio between GPP and autotrophic respiration is close to the expected value of 0.47 for Mugello and Maremma and lower (0.40) for Comelico, with marginal intra-area and inter-year variations (Table 3 ). This obviously affects the NPP and DM simulated by this model in the three cases. About half of predicted GPP is converted into NPP for Mugello and Maremma, while the fraction exceeds 0.6 for Comelico. The combination of the GPP and Ra estimation patterns provides DM estimates similar to those of C-Fix for Mugello and Maremma, but rather different from these for two Comelico sites (Fig. 5B). These correspond to the least and most elevated sites, where the likely inaccurate meteorological drivers determine strong under- and overestimation of DM.

The same figures show that both models have greater difficulty in reproducing inter-annual variations of accumulated DM. This issue, however, cannot be fully explored due to the limited number of years examined.

\section{Discussion}

\subsection{Calibration of the two models}

The data collected by eddy covariance towers are generally affected by uncertainties related to both methodological and site specific issues (Papale et al., 2006). Overall, eddy covariance data

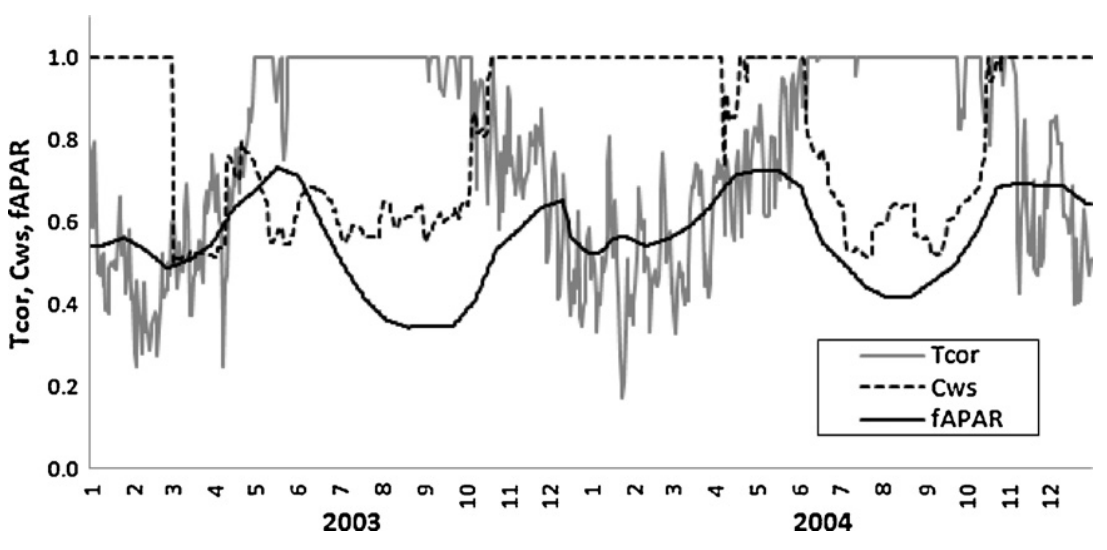

Fig. 3. Temporal evolution of the two C-Fix meteorological correction factors and of fAPAR for the Amplero site. 

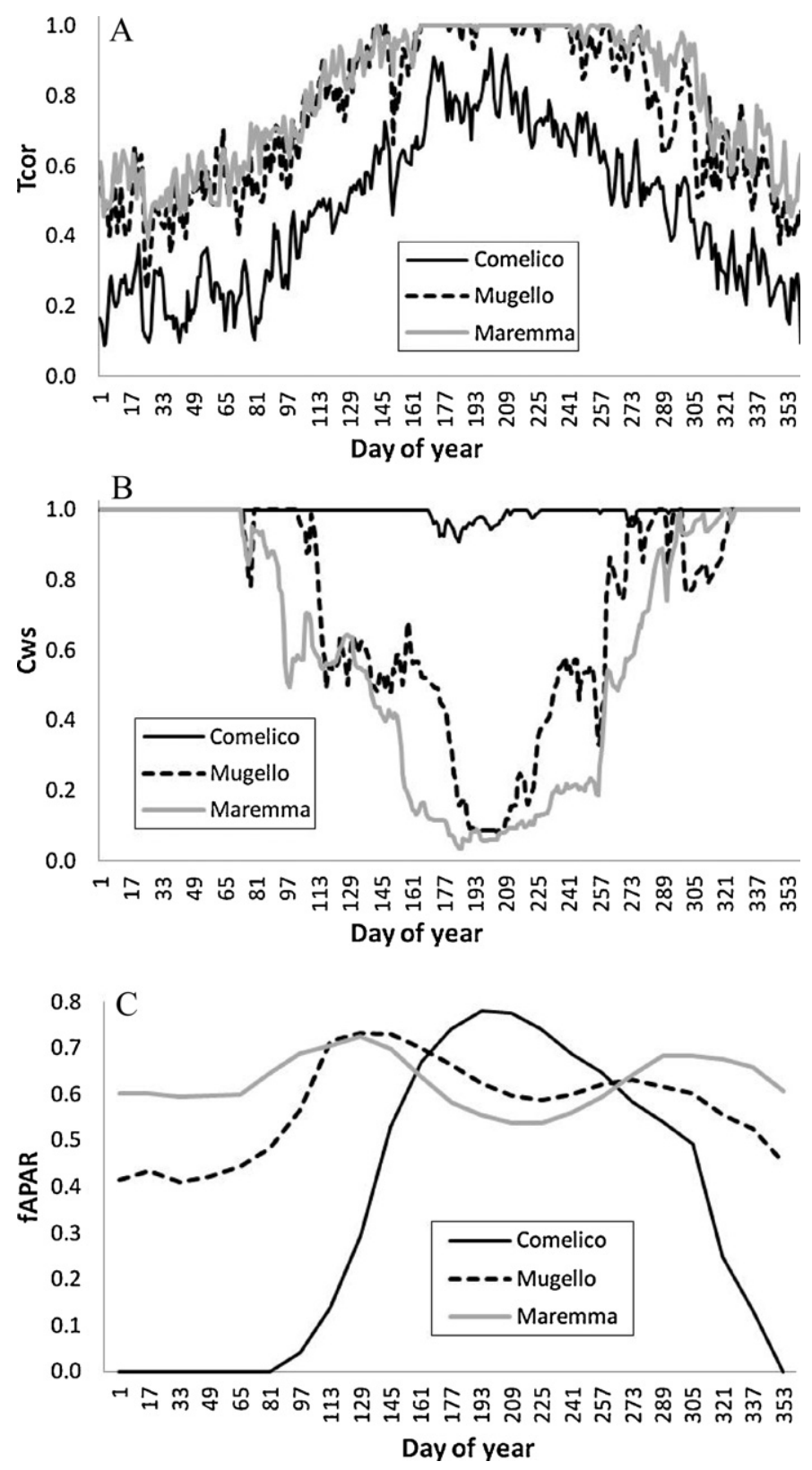

Fig. 4. (A-C) Mean $T_{\text {cor }}$, Cws and fAPAR annual profiles of the three NPP measurement areas for the respective study periods (2006-2008 Comelico, 2006-2007 Mugello, 2004-2007 Maremma).

processing is based on quality test algorithms that are aimed at identifying measurements that depart from ideal conditions and that are replaced by gap-filled values (Foken and Wichura, 1996). The amount of gap filled data can therefore be seen as an indicator of the 'goodness' of the data collected. This justifies the current conservative choice of considering only years with almost complete daily GPP series, which should guarantee a high quality of the reference dataset. Fortunately, the 2 years selected (2003 and 2004) presented extremely contrasting meteorology (dry and wet, respectively), which allowed a proper tuning of the model functions regulating relevant responses.

When compared to the measurements of other grassland sites, the annual GPP of Amplero ( $1400 \mathrm{~g} \mathrm{C} \mathrm{m}^{-2}$ year $^{-1}$ ) is rather high. For example, Zhang et al. (2007) found flux tower GPP measurements ranging from 500 to $900 \mathrm{~g} \mathrm{C} \mathrm{m}^{-2}$ year $^{-1}$. This can be mainly attributed to the more temperate climate of Amplero, whose grassland productivity is likely affected by lower thermal and water
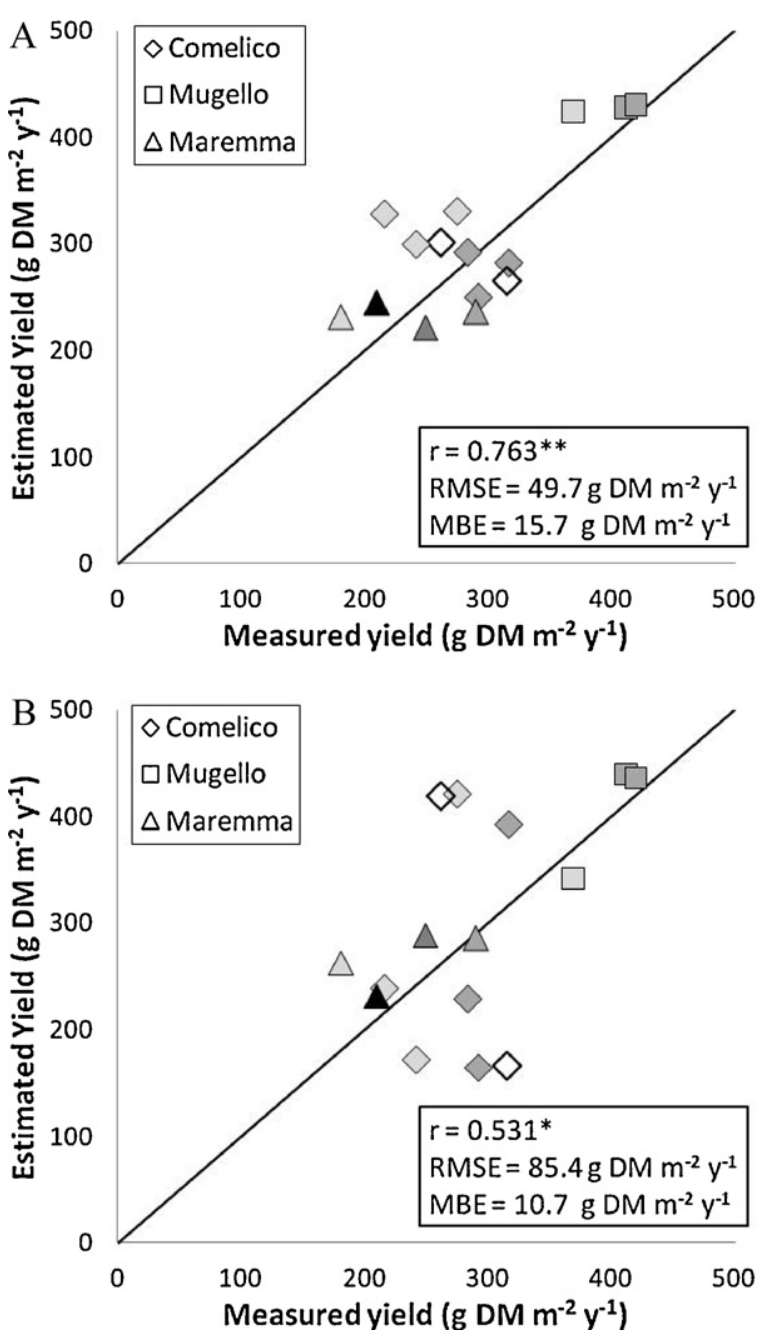

Fig. 5. Dry matter (DM) yield measured and estimated by C-Fix (A) and BIOME-BGC (B) at the three validation areas for the respective study periods. The grey tones of the symbols indicate the 5 years considered, from 2004 (black) to 2008 (white) ( ${ }^{*}$ significant correlation, $P<0.05$; **highly significant correlation, $P<0.01$ ).

limitations. The same is the case for the GPP found by Nagy et al. (2007) over a grassland site in Hungary during the same 2 years of the current study $\left(850 \mathrm{~g} \mathrm{C} \mathrm{m}^{-2}\right.$ year $\left.^{-1}\right)$. The Amplero and Hungarian sites, however, share a similar inter-annual GPP variability: the productivity of the extremely dry 2003 is much lower than that of 2004.

Both meteorological and remotely sensed model drivers can be assumed to be quite accurate for the Amplero site. A previous study in fact demonstrated that the E-OBS minimum and maximum temperatures downscaled to $1 \mathrm{~km}$ can faithfully reproduce ground measurements in plain or gently undulated areas (Maselli et al., 2012). Lower accuracy characterizes daily rainfall, which, for this reason, was mostly derived from the tower measurements. Concerning the remotely sensed data, the presence of a relatively large and homogeneous grassland surrounded by dense forest is expected to allow an efficient application of the method to extract NDVI values and, consequently, a correct estimation of fAPAR multitemporal profiles. In this case, in fact, the method extracts the NDVI values of areas with lowest green LAI, which are approximately coincident with the centre of the grassland.

Only slight modifications were needed to allow the C-Fix model to accurately estimate the reference GPP data. The MODIS temperature correction factor for grasses, which is conceived to be of global applicability, is well adapted for application to Italian 
grasslands. The computation of Cws from one-month water balance in place of the original two months accounts for the more rapid response to water stress of grasslands with respect to forests (Maselli et al., 2009b). The optimum maximum $\varepsilon$ found for grassland $\left(1.65 \mathrm{~g} \mathrm{C} \mathrm{MJ}^{-1}\right.$ (APAR)) is higher than that used by the MODIS algorithm (0.68 $\mathrm{g} \mathrm{CMJ}^{-1}$ (APAR)) (Heinsch et al., 2003). This discrepancy can be partly attributed to a lower downregulation brought by the MODIS water stress factor with respect to Cws. The former, in fact, is derived from large-scale estimates of vapor pressure deficit, whose limiting effect is generally lower than that of a site water budget (Chiesi et al., 2011). MODIS $\varepsilon$ is also much lower than the mean value obtained for grassland by Garbulsky et al. (2010) from the analysis of flux tower data (about $2.1 \mathrm{~g} \mathrm{C} \mathrm{MJ}^{-1}$ (APAR)). Actually, both Garbulsky et al. (2010) and Wang et al. (2010) showed that grasslands are characterized by an extreme $\varepsilon$ variability depending on local environmental features and management practices. The relatively high maximum $\varepsilon$ currently found would therefore indicate that the study grassland has a high production potential, which is reduced by temperature and water stresses. The relevance of these limitations is confirmed by the seasonal fAPAR profile of the grassland, which shows clear minima in both winter and summer.

The calibration of BIOME-BGC was slightly more complex, as it concerned two settings which regulate the model prediction of grassland production processes. The optimal model configuration was identified using a fraction of leaf nitrogen in rubisco and a maximum stomata conductance respectively higher and lower than the original grassland settings $\left(0.38 \mathrm{~m} \mathrm{~s}^{-1}\right.$ versus $0.15 \mathrm{~m} \mathrm{~s}^{-1}$ and $0.0027 \mathrm{~m} \mathrm{~s}^{-1}$ versus $0.005 \mathrm{~m} \mathrm{~s}^{-1}$ ). This is in accordance with the previously noted high production potential of the study grassland, which is evidently associated to a strong resistance to summer water shortage.

Both tuned C-Fix and calibrated BIOME-BGC provide accurate simulations of daily GPP at the Amplero site. The marginally better performance of C-Fix can be explained considering that this model is partly controlled by a remotely sensed estimator of absorbed solar radiation, which reflects the possible effects of the management practices applied. In contrast, BIOME-BGC is entirely driven by conventional environmental data and cannot reproduce these effects (see also below). The inaccurate simulation of the grassland growing phases in the second study year can also be attributed to the simplified representation of soil hydrology and plant phenology which is used by BIOME-BGC (Hidy et al., 2012).

\subsection{Simulation of NPP in the three validation areas}

The DM measurements collected in the three validation areas presented different spatial and temporal characteristics. In general, the representativeness of ground data depends on the number of grouped samples and on the spatial homogeneity of the observed sites. The number of forage samples and their distribution on the terrain were due to the different survey schemes planned and applied in previous investigations with the main aim of characterizing the pasture vegetation types (Staglianò et al., 2008; Messeri, 2009; Targetti et al., 2010). These numbers may therefore be suboptimal for the current characterization of pasture production. In all cases, however, attention was used to select homogeneous grasslands, which should guarantee that the samples collected were representative of wider areas with similar forage production. In mountain areas the environmental heterogeneity is higher than in Maremma and for this reason the number of samples was correspondingly higher. The Comelico area, in particular, is characterized by an extreme heterogeneity of topographic and, consequently, eco-climatic features. This also affects the botanical composition of the Comelico sites, whose diversification has obvious consequences on relevant DM production (Targetti et al., 2010). In contrast, the other two areas (Mugello and Maremma) show only marginal topographic variability, which is reflected in higher homogeneity of all relevant environmental and floristic characteristics (Staglianò et al., 2008; Messeri, 2009).

The meteorological data used to drive the two models in the three NPP validation areas could not be evaluated due to the lack of relevant ground measurements. The meteorology estimated for the mountain sites of Comelico, however, can be supposed to be the least accurate, due to the erroneous prediction of elevation by the 1-km DEM used to downscale the E-OBS weather data. The least and most elevated sites of this highly irregular area are, in fact, placed at 1850 and $2050 \mathrm{~m}$ a.s.l., while the corresponding DEM elevations are of 1880 and $2250 \mathrm{~m}$ a.s.l., respectively. These elevation overestimations are expected to cause overestimated temperature differences among sites. This problem is generally unavoidable when using low-medium spatial resolution DEMs in highly rugged terrain, where steep slopes can create great altitudinal gradients within each pixel. The meteorology estimated for the more regular areas of Mugello and Maremma is expected to be more accurate, due to the correspondence of real and DEM elevations in these gently undulated areas (differences lower than $50 \mathrm{~m}$ ).

Significant but still not evaluable errors likely affect the fAPAR estimates used to drive C-Fix. The accuracy of the extracted NDVI data, in fact, depends on the mean size and homogeneity of the observed grasslands. Consequently, relevant errors are expected to occur in all three study areas, where grasslands are fragmented and close to forests. All DM measurement sites were in fact placed at a small distance from forest boundaries, which created critical situations for the extraction of grassland NDVI values from $250 \mathrm{~m}$ spatial resolution MODIS imagery. The method currently applied could only attenuate this problem, which can cause different NDVI estimation errors. More particularly, in the Comelico area the adjacency of the study grasslands to evergreen conifers is expected to cause variable NDVI overestimations in dependence on the size (several hectares) and fragmentation of the grass plots. Different is the case for the two areas in Tuscany (Mugello and Maremma), where the presence of smaller grasslands (1-2 ha) intermingled with evergreen shrubs and deciduous forests may cause varying estimation errors in the different seasons. These errors are virtually unavoidable when using MODIS NDVI imagery in highly heterogeneous and fragmented areas which, as previously noted, are typical of most Mediterranean regions.

The conversion of GPP into cumulated DM required the use of additional coefficients, whose validity can be assessed only globally. In the case of C-Fix the first factor corresponds to the constant ratio between NPP and GPP, which was set equal to 0.53 following commonly accepted literature (Chen et al., 2003; Zhang et al., 2009). As previously noted, this method is theoretically less correct than that based on BIOME-BGC simulation of both GPP and autotrophic respiration. The effectiveness of this advantage, however, could not be clearly appreciated due to the problems encountered in applying this model in the Comelico area. The two factors used to transform NPP into cumulated DM are expected to have higher level of robustness. The first, used to convert carbon NPP into the carbon accumulated in the above ground compartment $(0.33)$ derives from the same modeling theory of BIOME-BGC (White et al., 2000). The second, used to convert carbon into dry matter (2), is commonly accepted for a variety of terrestrial vegetation types.

In general, the low mean DM bias obtained by the two models confirms the correctness of the calibrations performed, particularly concerning the two coefficients (maximum $\varepsilon$ and fraction of leaf nitrogen in rubisco) which regulate the respective photosynthetic potential. More specifically, the accuracy of NPP estimates obtained from the two models is dependent on the relative importance of the remotely sensed and meteorological drivers in the three areas. 
C-Fix and BIOME-BGC, in fact, are driven by different estimates of local eco-climatic conditions (through site parameters and meteorological data) and existing green biomass (through NDVI/fAPAR data). BIOME-BGC uses only conventional inputs descriptive of site environmental conditions and meteorology. The model is therefore sensitive to the accuracy of the drivers used and particularly to that of the weather data, which critically depends on the number of meteorological stations available, the interpolation/extrapolation method applied, and the topography of the areas observed (Matsushita et al., 2004; Chiesi et al., 2011). Moreover, the model can be expected to perform well in eco-climatic conditions similar to those of the calibration site, while it should have more problems in different cases. This explains the poor performance of BIOME-BGC in the mountain area of Comelico, where the great terrain altitude and irregular topography create extreme ecoclimatic conditions far from those of Amplero and negatively affect the quality of the estimated weather drivers. As previously mentioned, the model simulation of grassland fluxes is also affected by a simplified representation of soil hydrology and plant phenology and by the non consideration of possible management practices. A recent study of Hidy et al. (2012) has shown that both these factors could be taken into account only through a complex modification of relevant model functions.

C-Fix alleviates these problems thanks to a more direct prediction of grassland photosynthesis. In this case, in fact, GPP is simulated by combining weather and fAPAR estimates. The latter component, which is derived from remotely sensed NDVI data, is decisive in reducing the uncertainty coming from inaccurate meteorological drivers and particularly in estimating the main grass phenological stages and the effects of harvesting.

\section{Conclusions}

The calibration of C-Fix and BIOME-BGC was successful in identifying model input parameters which allow to accurately predict the daily gross carbon uptake observed at the Amplero study site. Since the site is affected by both temperature and water limitations, this result indicates that both models are capable of capturing the main factors which drive local grassland productivity. The calibration of the two models in only one site is, however, suboptimal, and improvements could be expected from the availability of flux measurements from additional tower stations. This confirms the importance of such measurements to better understand ecosystem processes and improve relevant models structures.

The two models examined perform differently when applied to the three NPP validation areas. Specifically, the combination of ground and remotely sensed drivers allows a greater stability of the C-Fix estimates. In contrast, the nearly complete dependence of BIOME-BGC on meteorological drivers limits the estimation accuracy achievable, particularly in the most irregular area of Comelico. This problem could especially concern the estimation of the growing season start and end, which are mostly derived from remotely sensed NDVI data when using C-Fix while can be only approximated on the basis of local meteorology by BIOME-BGC.

These considerations enhance the importance of having NDVI imagery which presents high radiometric quality and adequate spatial and temporal properties. The current availability of MODIS NDVI data is a step forward in this direction, which could be further improved by the advent of new sensors and/or the application of advanced data fusion techniques. The use of data with enhanced spatial resolution should be particularly rewarding in fragmented and heterogeneous environments which are typical of most Italian and, more generally, European areas.

\section{Acknowledgements}

The current research has been partly funded by the Italian Ministry of Education, University and Research under the FIRB2008 program, project "Modelling the carbon sink in Italian forest ecosystems using ancillary data, remote sensing data and productivity models" C_FORSAT (code: RBFR08LM04, national coordinator: G. Chirici). The support of the EU project GHG-Europe is also acknowledged.

The authors acknowledge the use of the E-OBS data set from the EU-FP6 project ENSEMBLES (http://ensembles-eu.metoffice.com) and the data providers in the ECA\&D project (http://eca.knmi.nl). The authors want to thank two anonymous AGEE reviewers for their helpful comments which improved the quality of the original manuscript.

\section{References}

Argenti, G., Bottai, L., Chiesi, M., Maselli, F., Staglianò, N., Targetti, S., 2011. Analysis and assessment of mountain pastures by integration of multispectral and ancillary data (Analisi e valutazione di pascoli montani attraverso l'integrazione di dati multispettrali e ausiliari). Ital. J. Remote Sens. 43, 45-57.

Balzarolo, M., 2008. Biometric parameters and fluxes estimations in Mediterranean mountainous grassland with remote sensing techniques. $\mathrm{PhD}$ thesis, University of Tuscia.

Bannari, A., Morin, D., Bonn, F., Huete, A.R., 1995. A review of vegetation indices. Remote Sens. Rev. 13, 95-120.

Baret, F., Guyot, G., 1991. Potentials and limits of vegetation indices for LAI and APAR assessment. Remote Sens. Environ. 46, 213-222.

Bolle, H.J., Eckardt, M., Koslowsky, D., Maselli, F., Melia-Miralles, J., Menenti, M., Olesen, F.-S., Petkov, L., Rasool, I., Van de Griend, A., 2006. Mediterranean land-surface processes assessed from space. Springer, Series: Regional Climate Studies, vol. XXVIII, p. 760.

Boschetti, M., Bocchi, S., Brivio, P.A., 2007. Assessment of pasture production in the Italian Alps using spectrometric and remote sensing information. Agric. Ecosyst. Environ. 118, 267-272.

Chen, X., Hutley, L.B., Eamus, D., 2003. Carbon balance of a tropical savanna of northern Australia. Oecology 137, 405-416.

Chiesi, M., Maselli, F., Moriondo, M., Fibbi, L., Bindi, M., Running, S.W., 2007. Application of BIOME-BGC to simulate Mediterranean forest processes. Ecol. Model. 206, 179-190.

Chiesi, M., Fibbi, L., Genesio, L., Gioli, B., Magno, R., Maselli, F., Moriondo, M., Vaccari, F., 2011. Integration of ground and satellite data to model Mediterranean forest processes. Int. J. Appl. Earth Obs. Geoinf. 13, 504-515.

Churkina, G., Tenhunen, J., Thornton, P., Falge, E.M., Elbers, J.A., Erhard, M., Grünwald, T., Kowalski, A.S., Rannik, U., Sprinz, D., 2003. Analyzing the ecosystem carbon dynamics of four European coniferous forests using a biogeochemistry model. Ecosystems 6, 168-184.

Coppa, M., Farruggia, A., Pradel, P., Lombardi, G., Martin, B., 2011. An improved grazed class method to estimate species selection and dry matter intake by cows at pasture. Ital. J. Anim. Sci. 10, 58-68.

Cramer, W., Kicklighter, D.W., Bondeau, A., Moore, B., Churkina, C., Nemry, B., Ruimy, A., Schloss, A.L., 1999. Comparing global models of terrestrial net primary productivity (NPP): overview and key results. Global Change Biol. 5, 1-15.

FAO, 2005. In: Suttie J.M., Reynolds, Batello, C. (Eds.), Grasslands of the World. Food and Agriculture Organization of the United Nations, Rome, $514 \mathrm{pp}$.

Foken, T., Wichura, B., 1996. Tools for quality assessment of surface based flux mesurements. Agric. For. Manag. 78, 83-105.

Garbulsky, M.F., Peñuelas, J., Papale, D., Ardö, J., Goulden, M.L., Kiely, G., Richardson, A., Rotenberg, E., Veenendaal, E.M., Filella, I., 2010. Patterns and controls of the variability of radiation use efficiency and primary productivity across terrestrial ecosystems. Global Ecol. Biogeogr. 19, 253-267.

Goetz, S.J., Prince, S.D., Goward, S.N., Thawley, M.M., Small, J., 1999. Satellite remote sensing of primary production: an improved production efficiency modeling approach. Ecol. Mod. 122, 239-255.

Haylock, M.R., Hofstra, N., Klein Tank, A.M.G., Klok, E.J., Jones, P.D., 2008. A European daily high-resolution gridded dataset of surface temperature and precipitation. J. Geophys. Res. (Atmospheres) 113, D20119, http://dx.doi.org/10.1029/2008JD10201.

Heinsch, F.A., Reeves, M., Votava, P., Kang, S., Milesi, C., Zhao, M., Glassy, J., Jolly, W.M., Loehman, R., Bowker, C.F., Kimball, J.S., Nemani, R.R., Running, S.W., 2003. User's Guide GPP and NPP (MOD17A2/A3) Products NASA MODIS Land Algorithm. Version 2.0, December 2, 2003 www.ntsg.umt.edu/modis/

Hidy, D., Barcza, Z., Haszpra, L., Churkina, G., Pinter, K., Nagy, Z., 2012. Development of the Biome-BGC model for simulation of managed herbaceous ecosystems. Ecol. Mod. 226, 99-119.

Maselli, F., 2011. Use of MODIS NDVI data to improve forest area-estimation. Int. J. Remote Sens. 32, 6379-6393.

Maselli, F., Gilabert, M.A., Conese, C., 1998. Integration of high and low resolution NDVI data for monitoring vegetation in Mediterranean environments. Remote Sens. Environ. 63, 208-218. 
Maselli, F., Papale, D., Puletti, N., Chirici, G., Corona, P., 2009a. Combining remote sensing and ancillary data to monitor the gross productivity of water-limited forest ecosystems. Remote Sens. Environ. 113, 657-667.

Maselli, F., Di Gregorio, A., Capecchi, V., Breda, F., 2009b. Enrichment of land cover polygons with eco-climatic information derived from MODIS NDVI imagery. J. BioGeogr. 36, 639-665.

Maselli, F., Pasqui, M., Chirici, G., Chiesi, M., Fibbi, L., Salvati, R., Corona, P., 2012. Modeling primary production using a 1-km daily meteorological data set. Clim. Res. 54, 271-285.

Matsushita, B., Xu, M., Chen, J., Kameyama, S., Tamura, M., 2004. Estimation of regional net primary productivity (NPP) using a process-based ecosystem model: how important is the accuracy of climate data? Ecol. Mod. 178, 371-388.

Messeri, A., 2009. Evoluzione di formazioni oligotrofiche in aree appenniniche (Evolution of oligotrophic resources in Apennine areas). PhD thesis, University of Florence, $185 \mathrm{p}$.

Monteith, J.L., 1966. The photosynthesis and transpiration of crops. Exp. Agric. 2, $1-14$.

Monteith, J.L., 1972. Solar radiation and productivity in tropical ecosystems. J. Appl. Ecol. 9, 747-766.

Myneni, R.B., Williams, D.L., 1994. On the relationship between fAPAR and NDVI. Remote Sens. Environ. 49, 200-211.

Nagy, Z., Pinter, K., Czobel, Sz., Balogh, J., Horvath, L., Foti, Sz., Barcza, Z., Weidinger, T., Csintalan, Zs., Dinh, N.Q., Grosz, B., Tuba, Z., 2007. The carbon budget of semiarid grassland in a wet and a dry year in Hungary. Agric. Ecosyst. Environ. 121, 21-29.

Papale, D., Reichstein, M., Aubinet, M., Canfora, E., Bernhofer, C., Kutsch, W., Longdoz, B., Rambal, S., Valentini, R., Vesala, T., Yakir, D., 2006. Towards a standardized processing of Net Ecosystem Exchange measured with eddy covariance technique: algorithms and uncertainty estimation. Biogeosciences 3, 571-583.

Paruelo, J.M., Golluscio, R.A., Guerschman, J.P., Cesa, A., Jouve, V.V., Garbulsky, M.F., 2004. Regional scale relationships between ecosystem structure and functioning: the case of the Patagonian steppes. Global Ecol. Biogeogr. 13 (5), 385-395.

Pearson, C.J., Ison, R.L., 1997. Agronomy of Grassland Systems. Cambridge University Press, Cambridge, p. 222.

Reichstein, M., Falge, E., Baldocchi, D., Papale, D., Aubinet, M., Berbigier, P., Bernhofer, C., Buchmann, N., Gilmanov, T. Granier, A Grünwald T., Havránková, K. Ilvesniemi, H., Janous, D., Knohl, A., Laurila, T., Lohila, A., Loustau, D., Matteucci, G., Meyers, T., Miglietta, F., Ourcival, J., Pumpanen, J., Rambal, S., Rotenberg, E., Sanz, M., Tenhunen, J., Seufert, G., Vaccari, F., Vesala, T., Yakir, D., Valentini, R., 2005. On the separation of net ecosystem exchange into assimilation and ecosystem respiration: review and improved algorithm. Global Change Biol. 11, 1424-1439.

Running, S.W., Hunt, E.R., 1993. Generalization of a forest ecosystem process model for other biomes, BIOME-BGC, and an application for global-scale models. In: Ehleringer, J.R., Field, C.B. (Eds.), Scaling Physiological Processes: Leaf to Globe. Academic Press, San Diego, pp. 141-158.
Soussana, J.-F., Loiseau, P., Vuichard, N., Ceschia, E., Balesdent, J., Chevallier, T., Arrouays, D., 2004. Carbon cycling and sequestration opportunities in temperate grasslands. Soil Use Manage. 20, 219-230.

Soussana, J.F., Allard, V., Pilegaard, K., Ambus, P., Amman, C., Campbell, C., Ceschia, E., Clifton-Brown, J., Czobel, S., Domingues, R., Flechard, C., Fuhrer, J., Hensen, A. Horvath, L., Jones, M., Kasper, G., Martin, C., Nagy, Z., Neftel, A., Raschi, A., Baronti, S., Rees, R.M., Skiba, U., Stefani, P., Manca, G., Sutton, M., Tuba, Z., Valentini, R. 2007. Full accounting of the greenhouse gas $\left(\mathrm{CO}_{2}, \mathrm{~N}_{2} \mathrm{O}, \mathrm{CH}_{4}\right)$ budget of nine European grassland sites. Agric. Ecosys. Environ. 121, 121-134.

Staglianò, N., Argenti, G., Gentili, G., 2008. Forage species for long duration artificial mixtures characterised by different complexity. In: Proceedings of 12th Subnetwork on Mediterranean Forage resources of FAO-CIHEAM, Elvas (P), 9-12 April 2008, Cahiers Options Méditerranéennes, vol. 79, CIHEAM Saragozza, pp. 157-160.

Targetti, S., Staglianò, N., Messeri, A., Argenti, G., 2010. A state-and-transition approach to alpine grasslands under abandonment. iForest, Biogeosci. Forest. 3, 44-51.

Thornton, P.E., Hasenauer, H., White, M.A., 2000. Simultaneous estimation of daily solar radiation and humidity from observed temperature and precipitation: an application over complex terrain in Austria. Agric. For. Meteorol. 104, 255-271.

Turner, D.P., Ritts, W.D., Cohen, W.B., Gower, S.T., Running, S.W., Zhao, M., Costa, M.H., Kirschbaum, A.A., Ham, J.M., Saleska, S.R., Ahl, D.E., 2006. Evaluation of MODIS NPP and GPP products across multiple biomes. Remote Sens. Environ. $102,282-292$.

van den Besselaar, E.J.M., Haylock, M.R., van der Schrier, G., Klein Tank, A.M.G. 2011. A European daily high-resolution observational gridded data set of sea level pressure. J. Geophys. Res. 116, D11110, http://dx.doi.org/10.1029/ 2010JD015468.

Veroustraete, F., Sabbe, H., Eerens, H., 2002. Estimation of carbon mass fluxes over Europe using the C-Fix model and Euroflux data. Remote Sens. Environ. 83, 376-399.

Veroustraete, F., Sabbe, H., Rasse, D.P., Bertels, L., 2004. Carbon mass fluxes of forests in Belgium determined with low resolution optical sensors. Int. J. Remote Sens. 25 (4), 769-792.

Wang, H., Jia, G., Fu, C., Feng, J., Shao, T., Ma, Z., 2010. Deriving maximum light use efficiency from coordinated flux measurements and satellite data for regiona gross primary production modeling. Remote Sens. Environ. 114, 2248-2258.

White, M.A., Thornton, P.E., Running, S.W., Nemani, R.R., 2000. Parameterisation and sensitivity analysis of the BIOME-BGC terrestrial ecosystem model: net primary production controls. Earth Int. 4, 1-85.

Wolfe, R.E., Nishihama, M., Fleig, A.J., Kuyper, J.A., Roy, D.P., Storey, J.C., Patt, F.S., 2002. Achieving sub-pixel geolocation accuracy in support of MODIS land science. Remote Sens. Environ. 83, 31-49.

Zhang, L., Wylie, B., Loveland, T., Fosnight, E., Tieszen, L.L., Ji, L., Gilmanov, T., 2007. Evaluation and comparison of gross primary production estimates for the Northern Great Plains grasslands. Remote Sens. Environ. 106, 173-189.

Zhang, Y., Xu, M., Chen, H., Adams, J., 2009. Global pattern of NPP to GPP ratio derived from MODIS data: effects of ecosystem type, geographical location and climate. Global Ecol. Biogeogr. 18, 280-290. 